\title{
Journal of Korean Medical Science (JKMS): influential flagship medical journal in the Republic of Korea
}

\author{
Jin-Hong Yoo ${ }^{1,2,3}, M D$, PhD, Jong-Min Kim ${ }^{1,4}$, MD, PhD, Kyung Pyo Hong ${ }^{1,5}$, MD, PhD, Jongmin Lee ${ }^{6,7}, M D$, PhD, \\ Sung-Tae Hong ${ }^{8,9}$ * MD, PhD \\ ${ }^{1}$ Deputy Editor, Journal of Korean Medical Science, Korea \\ ${ }^{2}$ Division of Infectious Diseases, Department of Internal Medicine, College of Medicine, The Catholic University of Korea, Seoul, Korea \\ ${ }^{3}$ Division of Infectious Diseases, Department of Internal Medicine, Bucheon St Mary's Hospital, Bucheon, Korea \\ ${ }^{4}$ Department of Neurology, Seoul National University Bundang Hospital, Seoul National University College of Medicine, Seongnam, Korea \\ ${ }^{5}$ Department of Medicine, Sungkyunkwan University School of Medicine, Seoul, Korea \\ ${ }^{6}$ Director of International Affairs, the Korean Academy of Medical Sciences, Korea \\ ${ }^{7}$ Department of Radiology, Kyungpook National University Hospital, Daegu, Korea \\ ${ }^{8}$ Editor-in-Chief, Journal of Korean Medical Science, Korea \\ ${ }^{9}$ Department of Tropical Medicine and Parasitology, Seoul National University College of Medicine, Seoul, Korea \\ *Corresponding author: hst@snu.ac.kr \\ Hong Kong Med J 2021;27:242-3 \\ https://doi.org/10.12809/hkmj215119
}

The Journal of Korean Medical Science (JKMS; https://jkms.org/) is an international, peer-reviewed Open Access journal of medicine published weekly in English. The journal is published by the Korean Academy of Medical Sciences and the Korean Medical Association. The JKMS aims to publish evidencebased scientifically written articles from various disciplines of the medical sciences. The journal welcomes articles of general interest to medical researchers, especially those that contain original information. Articles on the clinical evaluation of drugs and other therapies, epidemiologic studies of the general population, studies on pathogenic organisms and toxic materials, and the toxicities and adverse effects of therapeutics are welcome. The JKMS was founded in 1986 and was indexed in MEDLINE in 1989. In 1999, the journal launched a website and was included in Science Citation Index Expanded (SCIE). Through steady efforts thereafter, JKMS was finally included in Science Citation Index in 2005. In 2007, JKMS established its own online submission system, and in 2017, began to use a submission system provided by Editorial Manager (Aries Systems Corporation, North Andover [MA], United States). Since 2010, JKMS has been published all articles as Open Access under the terms of the Creative Commons Attribution-NonCommercial 4.0 International license. The JKMS is indexed/tracked/ covered by MEDLINE, PubMed, PubMed Central, Web of Science (SCIE), BIOSIS Previews, Scopus, Embase, Chemical Abstracts Service, KoreaMed, Synapse, KoMCI, KCI, and Google Scholar. In 2016, JKMS became a member journal of the International Committee of Medical Journal Editors (http://icmje. org/). The 2020 Journal Impact Factor of JKMS is 2.153 and total citation counts 9573 (Clarivate Analytics, 2021) while the CiteScore 2020 is 4.0
(Scopus, 2021).

Since boldly launching weekly publication in 2018, JKMS is currently published every Monday, 50 issues a year. ${ }^{1}$ The page layout of the articles was edited to a single-column format to provide the online audience with better readability and visuality. Article categories include Original Article, Review Article, Special Article, Case Report, Brief Communication, Editorial, Opinion, Correspondence, and Images in this Issue. Thanks to weekly publication, JKMS significantly reduced the interval between the submission of manuscripts and publication. This advantage is particularly evident in the rapid publication of articles in the field of coronavirus disease 2019 (COVID-19). For example, the first case report of COVID-19 in Korea was submitted on 31 January 2020, accepted on 2 February, and published online on 3 February. $^{2}$ As of 9 August 2021, 177 articles relating to COVID-19 have been published in JKMS (https://jkms.org/ index.php?main=COVID-19) and five of them have received $>100$ citations. ${ }^{3-6}$ In 2020 , JKMS received 1614 submissions, and the acceptance rate was $26.1 \%$. In 2020, a huge rush of COVID-19 papers was received and a special section was prepared.

The peer review of manuscripts is the most important step in journal publishing. We always thank dedicated reviewers for providing feedback to authors so that the manuscripts can be published in their best form. ${ }^{7}$ The JKMS evaluates reviewers by combining the number of complete reviews and the scores of their review comments, and awards the highest rated reviewers the Best Reviewer Award at the general assembly of the Korean Academy of Medical Sciences every year (https://jkms.org/index. php?main=reviewer).

The Yoon Kwang-Yull Medical Prize was jointly 
established by the Korean Academy of Medical Sciences and the Gasong Foundation in 2008. The prize was established to promote the noble spirit of late founder Yoon Kwang-Yull's devotion to social service and academic research support. The prize is given to the author who has published excellent papers in JKMS in the past decade and contributed the most to spreading the outstanding medical research from Korea to the world. In 2021, Dr Sang-joon Park (Myongji Hospital, Goyang, Korea) received the 12th prize (https://jkms.org/index. php?main=prize).

The JKMS is an influential flagship journal of Korea. It adheres to global standards of editing and publishing for the purpose of leading research in medicine, proposing and discussing controversial issues, and archiving evidence-based science. It introduces new editing strategy and achieves publishing updates and publication ethics in Korea. Furthermore, it provides a publication platform for international researchers with trustworthy rapid publishing following global standards.

The staff of JKMS include an Editor-inChief (Dr Sung-Tae Hong), three deputy editors (Dr Kyung Pyo Hong, Dr Jin-Hong Yoo, Dr JongMin Kim), a managing editor (Dr Jong-Min Kim), four section editors (Dr Armen Yuri Gasparyan, Dr Kyung Pyo Hong, Dr Jin-Hong Yoo, Dr Jong-Min Kim), one language editor (Ms Allison B Alley), one statistics editor (Dr Moo-Song Lee), one image editor (Dr Jeehyoung Kim), one social media editor (Dr Olena Zimba), 13 executive board members, and 77 members of 37 subspecialties as the editorial board (https://jkms.org/index.php?main=exboard). Two assistant editors (Ms Ye-jin Lee, Ms So-yeon Jung) work in the editorial office. Manuscript editing, online publishing, and website management services are provided by XMLink Publishing Co. (https:// xmlink.kr/; Seoul, Korea).

The JKMS will continue to fulfil its mission as an authentic scholarly journal providing global readers with academically validated theories. In this context, we are sincerely pleased to have the opportunity to introduce the Hong Kong Medical Journal (HKMJ) under agreement between the Korean Academy of Medical Sciences and the Hong Kong Academy of Medicine. ${ }^{8}$ The JKMS and HKMJ will collaborate for mutual benefit and synergistic contribution in medical science.

\section{References}

1. Hong ST. Fostering strategic changes in publishing: Journal of Korean Medical Science in 2018. J Korean Med Sci 2018;33:e8.

2. Kim JY, Choe PG, Oh Y, et al. The first case of 2019 novel coronavirus pneumonia imported into Korea from Wuhan, China: implication for infection prevention and control measures. J Korean Med Sci 2020;35:e61.

3. Korean Society of Infectious Diseases, Korean Society of Pediatric Infectious Diseases, Korean Society of Epidemiology, Korean Society for Antimicrobial Therapy, Korean Society for Healthcare-associated Infection Control and Prevention, Korea Centers for Disease Control and Prevention. Report on the epidemiological features of coronavirus disease 2019 (COVID-19) outbreak in the Republic of Korea from January 19 to March 2, 2020. J Korean Med Sci 2020;35:e112.

4. Kim ES, Chin BS, Kang CK, et al. Clinical course and outcomes of patients with severe acute respiratory syndrome coronavirus 2 infection: a preliminary report of the first 28 patients from the Korean cohort study on COVID-19. J Korean Med Sci 2020;35:e142.

5. Ahn JY, Sohn Y, Lee SH, et al. Use of convalescent plasma therapy in two COVID-19 patients with acute respiratory distress syndrome in Korea. J Korean Med Sci 2020;35:e149.

6. Lee Y, Min P, Lee S, Kim SW. Prevalence and duration of acute loss of smell or taste in COVID-19 patients. J Korean Med Sci 2020;35:e174.

7. Hong ST. Appreciation to reviewers for the Journal of Korean Medical Science in 2020. J Korean Med Sci 2021;36:e60.

8. Li KK, Ma ES, Lui RN, Huang J, Xue H, Wong MC. Hong Kong Medical Journal-the Premier General Medical Journal in Hong Kong. J Korean Med Sci 2021;36:e226. 